\title{
GENETIC PRIVACY: THE POTENTIAL FOR GENETIC DISCRIMINATION IN INSURANCE
}

\author{
Pamela Jensen*
}

Beware of geneticists bearing discoveries. Their findings, perhaps more than any others in science, are likely to be abused and harmfully misinterpreted in the future...blue-eyed 'designer babies'....are not the real danger...Look instead at insurance companies...[t]hat is where the trouble is brewing. ${ }^{1}$

This thought-provoking quotation highlights the impact of the explosion in genetic technology which has occurred over the past decade. The threat of modern genetics has been perceived as coming, rather dramatically, from genetic engineering, but the less flashy field of medical genetic testing poses significant and immediate issues. ${ }^{2}$ Those issues are addressed in this paper.

\section{INTRODUCTION}

Medical genetics increasingly presents the possibility of making predictive genetic diagnoses in healthy persons by identifying genes that may dispose to or lead to illness in later life. For diseases that are preventable or treatable that is a decided benefit to the individual, but identification of an increased risk of becoming affected with a disorder that is not preventable or treatable offers new dilemmas.

* This is an edited version of a paper submitted in fulfilment of the VUW LLB(Hons) legal writing requirement.

1 A Gottlieb "Are Your Genes Up to Scratch?" The World in 1991 (1990) 18.

2 The terms "genetic testing" and "genetic screening" are often used interchangeably, although there is a difference between: (1) testing an individual for a condition suggested by evidence such as clinical signs and symptoms and/or family history; and (2) screening an individual of a population for a genetic defect without prior evidence of its existence in the individual. Both terms are used in this paper, and context should assist the reader. 
One of the most pressing concerns is the potential for breach of confidentiality or invasion of privacy. In analysing privacy issues the extent and circumstances in which it is appropriate to invade the privacy of another must be considered. There are three parts to this question: the acquisition of information, the disclosure of information, and the potential for prejudicial use of that information by third parties. ${ }^{3}$ A breach of privacy can result in an economic harm if a person is refused insurance on the basis of genetic test results.

Policy makers must consider whether genetic test results are to be regarded as an extension of general medical information to be made available in similar circumstances, or whether they should they be treated as a new class of information, subject to a different set of considerations. The law must be able to respond to concerns about the potential abuse of genetic information by third parties such as insurers. It will be important to balance the valuable research and medical information becoming available against the potential for discrimination.

Legislative responses to the important policy questions concerning the privacy and control of genetic information have not kept pace with the recent rapid advances in medical science and technology, so that inadequate protection is afforded to genetic privacy in the present environment.

\section{GENETIC INFORMATION: PRIVACY, CONFIDENTIALITY, AND DISCLOSURE TO THIRD PARTIES}

\section{A Is Genetic Information Any Different From Other Medical Information?}

One of the most important questions to be considered is whether genetic information is merely one form of medical information, or whether it is so different from other clinical data that it deserves special legal protection. There is precedent for this. Society traditionally accords a special level of protection to psychiatric records and to sexual health information, particularly HIV test results. Public perceptions also have a significant impact on this question. An individual's genetic makeup is generally considered to be different from other medical information for a number of reasons. Without doubt, the fact that genetic information is both predictive and familial causes the greatest concern. ${ }^{4}$ Information gained from genetic tests may predict future risks for

3 In this paper, references to "third party" and "third parties" do not refer to family members. The terms refer, in particular, to those who seek to make commercial gain by discriminating against individuals on the basis of their genotype. In this paper, the writer refers almost exclusively to insurance companies.

4 D Chambers "The Bowles Symposium on Genetic Technology and Underwriting" (1998) 14 On The Risk 2. 
healthy individuals, and can also reveal both present and future health information about biological relatives of the individual tested, in a way that no other medical information can.

The United States Task Force on Health Records and Genetic Privacy ${ }^{5}$ has emphasised the importance of giving special protection to genetic information, even if that involves doctors keeping genetic information separate from other patient information. The ability to treat genetic information with special care depends on how well it can be separated from other clinical information. In this paper, genetic information is defined broadly to include results of genetic testing, along with information about inherited characteristics obtained from a family history

Currently, genetic test results, along with other genetic information such as patient family history, will form part of a patient's medical record. An individual's right to privacy includes the right to control personal information, which includes the right to limit the collection, disclosure, and use of the personal information they have given to a medical practitioner. Medical confidentiality reflects the importance placed on this privacy and, for the reasons outlined above, genetic information is worthy of special protection.

If doctors had no duty to keep personal information confidential, then people might refuse medical treatment or withhold information which could seriously affect their doctor's ability to correctly diagnose and treat them. From a patient's perspective there is a very strong expectation that strict confidentiality will be kept in the doctor/patient relationship. Privacy and confidentiality are at the heart of the therapeutic relationship, with confidentiality an important tool for protecting privacy. The obligation upon doctors not to disclose information about patients can be found in medical professional ethics, legislation and the common law. ${ }^{6}$

\section{B Patient Confidentiality and Medical Professional Ethics}

The ethical conduct of health professionals is governed by a range of ethical codes. The first is the Hippocratic Oath: ${ }^{7}$

Whatever in connection with my professional practice, or not in connection with it, I see or learn, in the life of a man, which ought not to be spoken abroad, I will not divulge, as reckoning that all such should be kept secret.

5 Established in 1997 by the Commerce Committee of the United States House of Representatives.

6 See generally David B Collins Medical Law in New Zealand (Brooker \& Friend Ltd, Wellington, 1992).

7 Hippocratic Oath, Hippocrates, 5 BC. 
More recent codes have been developed to take into account modern ethical dilemmas. ${ }^{8}$ The New Zealand Medical Association Council Code of Ethics 1989, states that all doctors have a responsibility to their patients to: ${ }^{9}$

Keep in confidence information derived from a patient, or from a colleague regarding a patient, and divulge it only with the permission of the patient except when the law requires otherwise.

The position appears to be clear. A doctor can only disclose information when permitted by a patient or required by law. A practitioner who breaches this duty may be subject to Medical Disciplinary Tribunal proceedings.

Traditionally, this duty of confidentiality owed by a health professional to a patient has provided an appropriate means by which personal health information has been kept secure. In the case of genetic information, however, there is the potential for that duty of confidentiality to become strained. The realm of genetic testing and eligibility for health or life insurance cover gives rise to a potential displacement of both the traditional patient expectation of confidentiality and the duty of the practitioner to maintain it.

Dr Joanne Dixon, Medical Geneticist ${ }^{10}$ stated at the 1995 Privacy Issues Forum that:

I have now had numerous requests for information about tests, results, and implications of a diagnosis for a patient. These requests have occurred after patients have revealed testing as part of their application, or where information emerged in a doctor's report (with the patient, in one case, quite unaware of the proposed diagnosis).

Her policy is to insist on written consent from the patient before any information is released. ${ }^{11}$ A further example relevant in the context of genetic information privacy

8 See generally the Declaration of Geneva 1948; the World Medical Association International Code of Ethics 1949, 1968 and 1983; The Declaration of Helsinki, 1964, 1975 and 1983; the Declaration of Oslo 1970 and 1983; the Declaration of Tokyo 1975; the Declaration of Lisbon 1981; and the Declaration of Venice 1983.

9 The New Zealand Medical Association (NZMA) Code of Ethics 1989 endorses the international codes listed above $\mathrm{n}$ 13. All of these codes sanction modern versions of the Hippocratic Oath. In addition, members of the New Zealand Medical Association also acknowledge the spirit of the World Medical Association Code of Ethics (1949, 1965, and 1983).

10 Medical Geneticist, Central Regional Genetic Service; Director of the Cytogenetics and Molecular Genetics Laboratories, Capital Coast Health; Clinical Lecturer, Department of Pathology, Wellington School of Medicine.

11 Dr Dixon also fields enquiries from the courts. In relation to a custody dispute, one parent was at risk of a genetic condition. In a criminal case a patient had apparently revealed in his own defence, that he had recently undergone pre-symptomatic testing for a genetic condition. 
occurs when a doctor is employed by an insurance company for the purpose of medically assessing applicants and the reimbursement claims of those already insured.

The New Zealand Medical Association Code of Ethics 1989 states that a practitioner must "[o]nly enter a contract with an organisation if it will allow the maintenance of professional integrity."12 It is reasonable to expect that a doctor employed by an insurance company would ensure that the person she is examining understands that the usual doctor/patient relationship does not exist, and that any information disclosed will be recorded on a person's file. Less clear is the intended application of the following requirements which appear under the heading "Responsibilities to Society: Provision of Service in a Competitive Environment": ${ }^{13}$

47 Doctors must at all times regard their duty to a patient..., as overriding any loyalty to an employer... . In particular, doctors must not allow the commercial interests of an employer... to interfere with;

(a) the free exercise of clinical judgment in determining the best ways of meeting the needs of individual patients or the community[.]

49 Standards of care should not be compromised in order to meet financial or commercial targets...set...by an organisation.

These statements are instructive if they can be interpreted as applying to the role and duties of a doctor employed by an insurance company to conduct medical examinations or assess and verify claims. It is hardly contentious to say that the insurance environment is competitive. The fact that a doctor is required to place her duties to her patients over and above loyalty to her employer is good news indeed for insurance applicants and claimants. Finally, if an insurance company comes within the definition of "organisation", then a doctor is advised to allow standards of patient care to trump the company's financial or commercial targets. Although ethical duties can be overridden by the law, they are a sound platform on which to found an argument to support patient expectations within a clinical relationship.

12 NZMA Code of Ethics, para 30 [Code of Ethics].

13 Code of Ethics above n 12, paras 47, and 49. 


\section{Patient Confidentiality and the Common Law}

Although there are common law exceptions to the duty on doctors to keep information about patients confidential, disclosure must not be made lightly or without good cause. ${ }^{14}$ Legal decisions on confidentiality stress the important public interests served by respecting patient confidences. As stated in the case of $X v$ Y: ${ }^{15}$

...[i]n the long run, preservation of confidentiality is the only way of securing public health; otherwise doctors will be discredited as a source of information, for future patients 'will not come forward if doctors are going to squeal on them'.

\section{Patient Confidentiality and Medical Privilege in the Statutory Context}

In New Zealand, the duty of confidentiality is formalised in a number of statutes which prohibit some health professionals from disclosing information about patients to third parties. ${ }^{16}$ In this context a further concept contributes to the relationship of confidence between doctor and patient.

Medical privilege is founded in section 32 of the Evidence Amendment Act (No 2) 1980. It can be defined as the immunity which some medical people have from disclosing in court proceedings "protected communications" from patients. ${ }^{17}$ Relevant exceptions to this prohibition are where the patient consents to the information being divulged, or where the information was given in connection with the taking out of life insurance.

The "insurance exception" found in section 32(2)(b) states that medical privilege does not attach to: 18

The disclosure of any communication made to a registered medical practitioner in or about the effecting by any person of an insurance on the life of himself or any other person.

When a person undergoes a medical examination by their own doctor pursuant to a life insurance application, insurance companies usually require applicants to waive

14 See $W v$ Edgell [1990] 1 All E R 835, 851: "[O]nly the most compelling circumstances would justify a doctor in acting in a way which would injure the immediate interests of his patient, as the patient perceives them, without his consent."

$15 X v$ X [1988] 2 All ER 648, 653.

16 Evidence Amendment Act (No 2) 1980; Hospitals Act 1957; Area Health Boards Act 1983.

17 "Protected communication" means a communication made to a registered medical practitioner by a patient who believes that the communication is necessary to enable the registered medical practitioner to examine, treat, or act for the patient.

18 Evidence Act (No 2) 1980, s 32(2)(b). 
medical privilege. The insurance exception also recognises that the person making the communication need not be a patient, as is the case when an insurance company arranges for a life insurance applicant to be medically examined by a doctor engaged by the company. In this situation the doctor's employment contract with the insurer overrides the usual expectation of doctor/patient confidentiality.

\section{E Exceptions to the Duty of Confidentiality - When is Disclosure Justified?}

The concept of medical confidentiality is not inviolable. The law recognises that in some circumstances the interests of society may outweigh the desirability of maintaining medical confidentiality. Most of these exceptions to the general rule are found in law, ${ }^{19}$ although there are some circumstances where ethical and moral demands require confidential information to be divulged. ${ }^{20}$ It is important to note that ethical duties not to disclose information about patients can be overridden by any statutory or common law requirement to disclose such information.

Under Rule 11(1)(b) of the Health Information Privacy Code 1994, specific exemptions apply where the patient gives written and valid consent to disclose particular information. Insurance medical reports are common examples, and these are considered in a later part of this paper. Individual practitioners are at risk when their employer seeks information which a patient/client may not have authorised. It is important that a patient appreciates exactly which information she is authorising her doctor to disclose to a third party, along with any possible consequences of that disclosure. Wherever possible a patient should be advised against consenting to a blanket authority. A new consent should be given if further information is sought by the insurance company. ${ }^{21}$

\section{F Concluding Comments}

The fact that genetic information is both predictive and familial means that it is worthy of special protection. Just as recognition of the special nature of personal genetic information is an essential step towards protecting an individual's right to genetic privacy, it is also important to acknowledge the potential for the bounds of the traditional

19 For example: Health Act 1956; Contraception, Sterilisation and Abortion Act 1977; Accident Rehabilitation and Compensation Insurance Act 1992; Civil Aviation Act 1990; Health Act 1956; Misuse of Drugs Act 1975; Medicines Act 1981.

20 Outside the ambit of this paper is the issue of the existence and application of a duty to warn blood relatives in respect of genetic information.

21 Subject to the accident compensation legislation, breaches of confidence could well be actionable in tort in New Zealand, so that a patient could claim damages. Litigation is, however, expensive in terms of both time and money. 
doctor/patient relationship to become strained when negative economic consequences could flow from a breach of patient confidentiality.

Genetic data must be particularly protected from third party interest and disclosure, as these data can be considered the core of an individual's person. Genetic data should only be accessed by third parties in specific instances, and when the tested individual has been completely informed of the usefulness and purpose of passing on the data, and has given written permission to release them. In each individual case the doctor should consider whether the data is absolutely relevant to the question at hand and to the person seeking disclosure, and whether the patient is aware of all of the facts that may be relayed as well as the significance and possible consequences of relaying that information. These obligations clearly go beyond the general concept of confidentiality in medical practice.

\section{THE POTENTIAL FOR GENETIC DISCRIMINATION AND THE NEED FOR LEGAL PROTECTION OF GENETIC INFORMATION}

Genetic testing may reveal information which can be used to the benefit of an individual or to discriminate against an individual. ${ }^{22}$ While literature furnishes rich examples of the uses and abuses of genetics ${ }^{23}$, history too offers up many repugnant examples of past abuses of genetics. The very word "eugenics" conjures up images of Hitler's infamous "racial cleansing" and other atrocities which occurred under the guise of scientific advancement and social and economic salvation in Nazi Germany. The United States has also, at various times in its history, dabbled in eugenics. ${ }^{24}$

For detractors inclined to suggest that eugenics is a thing of the past, it is sobering to read that China recently passed a eugenic law compelling all couples to undergo premarriage testing for, among other things, serious hereditary diseases. ${ }^{25}$ Individuals

22 Information about a susceptibility to a particular disease or condition can enable an individual to make lifestyle and other decisions which may decrease their chance of developing the condition. Alternatively, the same information could result in the individual being denied insurance cover.

23 For example: HG Wells The Island of Doctor Moreau (1896) and Aldous Huxley Brave New World (1932).

24 The Supreme Court in Buck v Bell 256 US 689 (1927) held that eugenics by involuntary sterilisation of the mentally subnormal was constitutionally acceptable. In the early 1970's, legislation was enacted to mandate screening for the sickle cell trait in blacks applying for marriage licences. The debacle resulted in some insurers basing their decisions on test results. As recently as 1988, the United States Office of Technology Assessment suggested that human mating should not proceed without the use of genetic data, and that carriers of defective genes should use non-natural insemination strategies.

25 Article 10, Law on Maternal and Infant Health Care 1995 (as cited in Statement on the New Chinese Law Concerning Maternal and Child Health Care, Committee for Public Relations and Ethical Issues of 
suffering from, or carrying the gene for, any hereditary disease must be sterilised or agree to long-term contraception. All pregnancies are to be screened, and abortion is mandatory if the pregnancy is affected by genetic disease or other congenital defect.

In liberal democracies such as New Zealands, the new eugenics is bound to be much more subtle, working through the market rather than the state. It will be founded on the new medical paradigm that every major disease has a genetic component and that our likelihood of developing disease depends in part upon our genes. It is also thought that susceptibility to environmental factors and infections is partly genetic. People will increasingly come to think of good health as a matter of having healthy genes. Medical practice will increasingly involve gene management and manipulation.

Society will be faced with ethical, moral and social dilemmas as it considers whether it would be irresponsible to deliberately bring a disabled child into the world. Although individuals will be faced with the eugenic decisions, the end result will be the same - an attempt to 'improve' the genes of the next generation. Writers even now decry "the rise of a new eugenics" 26 which they describe as a product not of state policy, but of "social and institutional pressure". ${ }^{27}$

The greatest danger is perceived as coming from the use of predictive susceptibility or predisposition testing for multi-factorial diseases. ${ }^{28}$ Genetic tests are still poor predictors when it comes to such conditions and many individuals who are carriers will never show manifestations of their genotype. ${ }^{29}$ Modification of diet, exercise and lifestyle choices can, along with medical management, limit the expression of the gene. Inaccuracy of testing and variable test interpretation exacerbate the potential for discrimination in the absence of adequate regulatory protection.

'Genetic discrimination' may be defined as discrimination against an otherwise healthy individual on the basis of a genetic variation which may predispose her towards suffering from a disease or condition in the future. It is unacceptable for discriminatory

the German Society of Human Genetics) <http://omnibus.ruf.uni-freiburg.de/ gwolff/ e_china.htm>.

26 D Nelkin and M S Lindee The DNA Mystique: The Gene as a Cultural Icon (W H Freeman, New York, 1995.)

27 Above $\mathrm{n} 26$.

28 Multi-factorial (also known as polygenic) diseases result from the additive effect of a number of factors, some genetic, others environmental or unknown. This vast group of diseases includes most of the chronic diseases of later life.

29 Genotype refers to an individual's genetic makeup as opposed to phenotype, which refers to the physical manifestation of an individual's genotype, as a result of interaction with the environment. 
practices to be based on immutable characteristics such as hair colour, race or sex. Also to be avoided is the formation of a new social underclass based on genetic discrimination - the asymptomatic or 'healthy ill' whose only abnormality lies in their genes. The challenge is to anticipate the possible abuses of genetic information and to ensure that appropriate ethical and legal safeguards are set in place.

\section{COMMERCIAL APPLICATIONS OF GENETIC INFORMATION - GENETIC DISCRIMINATION IN INSURANCE ${ }^{30}$}

\section{A How Insurance Works and the Potential for Discrimination}

Genetic information provides serious challenges to the traditional operation of insurance. Insurance is designed to provide financial protection against inescapable harms and unexpected loss, and is based on the concepts of risk-spreading and risksharing. When the future health risks of a group of people are unknown, the future health care costs of the group can be predicted on an aggregate, actuarial basis, and the costs spread across the whole group. Life and health insurance in New Zealand are premised on the notion that risks can be predicted on a population-wide basis. Consequently some $95 \%$ of proposals are accepted on standard terms, ${ }^{31}$ even though there is always a great variation in the likelihood of any particular individual making a claim against the insurer.

Genetic technology, however, is making it possible to identify which people are likely to develop particular diseases at some time in the future, and insurance companies have begun to target them for individual assessment ${ }^{32}$ and special treatment - higher rates or denial of coverage. It is already accepted policy for health insurers to refuse to cover preexisting conditions, but predictive susceptibility genetic testing now provides an enormous loophole for insurers to classify numerous diseases or medical conditions as pre-existing when prospective insurance candidates carry a susceptibility gene. In the extreme, that approach could render everyone uninsurable as every human carries between 8 and 12 "defective" genes that might trigger various medical disorders. ${ }^{33}$

30 In this paper, "insurance" does not refer to real estate and chattels insurance, but refers instead to life, health, and income and mortgage protection insurance.

31 Errol Bateman, Insurance Underwriter, Royal \& Sun Alliance Insurance (Telephone interview, Wellington, 12 August 1997).

32 Household and motor vehicle insurance policies are individually assessed. The term "proposer" refers to a person requesting insurance cover from an insurance agent, broker or company. In this paper, "proposer" will be used interchangeably with the term "applicant".

33 L Andrews "Body Science" (1997) 83 ABAJ 44, 46. 
There is a silver lining to the cloud. In the past an individual with, for example, a family history of Huntington's chorea, ${ }^{34}$ would have been refused life insurance or charged a high premium even though no symptoms were present. The insurer could not know if the individual would develop the disease but knew that there was a $50 \%$ chance of it happening. Now that the test for the disease is almost $100 \%$ accurate, those with a family history of the disease can receive full insurance at standard rates if they test negative.

On the other hand, an insurance applicant who has undergone genetic testing, and whose results indicate a high risk of prematurely suffering from a debilitating illness, or even dying, should not be permitted to anti-select against the insurer by taking out a very large policy. "Anti-selection" or "adverse selection" occur when an individual contrives to gain an unreasonable benefit in return for premiums paid. Other policyholders are eventually adversely affected when they are required to pay higher premiums to subsidise the high level of claims made by a member of the pool of individuals insured at standard rates.

An interesting analogy can be made with car insurance. Research shows that consumers agree with the notion that "people should pay different rates for car insurance based upon the degree of risk they represent to the insurance company". But when the word "health" is substituted for "car" the consumer attitude is quite different. ${ }^{35}$ But can that be fair, when an applicant has no control over his genetic makeup? In order to be able to price insurance according to the risk, insurers simply need to know as much about the applicant's health history as the applicant knows. They do not need to know more.

Exclusions based on voluntarily assumed risks, such as cigarette smoking and hazardous pursuits, are perceived as somehow acceptable, but are less so when based on genetic differences. The distinction which is drawn between factors which are a matter of choice and genetic characteristics over which a person has no control, is the basis for the argument that higher premiums should only be charged when there is an element of fault on the part of the insured, as in the car insurance example above.

If, through the use of genetic information, insurers can learn of an individual's potential future health risks, such as a serious late-onset disorder, the benefits of risk-

34 Huntington's chorea, a monogenic disorder caused by a single gene mutation, is a slow wasting disease in which the patient's progressive mental and physical disability leads to involuntary movements, dementia and then premature death. The disease is still incurable and if someone carries the gene they will get the disease, although they may be asymptomatic until they are aged 50 or older.

35 P Brockett "Genetic Testing, Insurance Economics and Societal Responsibility" paper presented at the Bowles Symposium, 1997. 
spreading will be lost. Insurance companies would then be dealing more in certainties than in probabilities. The ability to identify and exclude high risk individuals could result in the paradoxical situation of insurance being most readily and affordably available to those who need it least. For individuals at risk, insurance may become prohibitively expensive. Individuals may respond by refusing to be tested, for fear of becoming part of an uninsurable underclass. A refusal to be tested is not desirable from either a personal or public health perspective. A study at an American university has shown that: ${ }^{36}$

...[P]eople who are using genetic testing are losing their insurance. And other people who should avail themselves of genetic testing are losing their lives to save their insurance.

There is a tension between those individuals who wish to exercise their right to know their genetic makeup, yet keep that information private, and insurance companies which claim that individuals should not be entitled to deprive them of information that could impact on the company's commercial interests. ${ }^{37}$ A further and even more complex tension is developing between individuals who do not wish to know their genetic makeup but still wish to be insured on standard terms, and insurers who may wish to gather more detailed medical information about an applicant via genetic testing.

If an individual cannot buy insurance without taking a genetic test, that is, arguably, a coercive and unethical business practice. Insurers are obliged to treat applicants and policyholders fairly. Overarching these tensions is the inherent conflict in insurance. Both insurers and policy-holders seek to maximise their own returns. That conflict notwithstanding, there is an obligation on both parties to act in utmost good faith when entering an insurance contract. ${ }^{38}$

\section{B Concluding Comments}

A decision to be tested for genetic mutations should be made by an individual with the advice of their medical practitioner, and not at the suggestion or behest of an

36 Nancy Wexler, Psychologist, Columbia University, New York. Ms Wexler was a member of a team who identified the specific gene for Huntington's disease in 1993. She believes that people have a right not to know their own genetic makeup. Wexler herself has at a $50 \%$ risk of developing Huntington's - the disease which killed her mother.

37 See also: Business Week Online News, 24 October 1996, 1. A survey by Georgetown University scientists asked 332 people with genetic disorders in 44 states if they had encountered problems getting health or life insurance. Some $25 \%$ said they were denied life insurance, while $22 \%$ were refused health insurance. It is outside the ambit of this paper to discuss the potential for genetic discriminatory practices by employers educational institutions, courts, mortgage brokers, adoption agencies and the armed forces.

38 The principle of uberrima fides, utmost good faith, is a legally accepted tenet of insurance. 
insurance underwriter. The right to choose or refuse to undergo medical tests or procedures, after being presented with the risks, benefits and alternatives, is well established in both medical practice and law. If insurers were able to insist that an applicant or policyholder undergo genetic testing, an unwilling applicant may receive knowledge that they or family members do not wish to have. That would result in a loss of privacy and a potential loss of insurability, which is an economic loss.

\section{$V$ WHAT CAN BE DONE TO SAFEGUARD INDIVIDUAL GENETIC PRIVACY AND PREVENT GENETIC DISCRIMINATION?: MODELS OF REGULATORY PROTECTION OF GENETIC INFORMATION}

\section{A International strategies}

World-wide interest in, and reaction to the benefits and challenges of, the Human Genome Project (the "HGP") have resulted in a plethora of both international and national efforts to protect private genetic information by regulating its collection and use by insurance companies. A recent World Health Organisation report describes two basic approaches to protecting genetic data from access by insurers: ${ }^{39}$

The first is to protect privacy by making access to information about an individual impossible, even with that individual's consent... . The second approach is to allow access to information but prevent it being used for a discriminatory purpose.

A Preliminary Draft for a Universal Declaration on the Human Genome and Human Rights states unequivocally that: "[T]he confidentiality of genetic data associated with a named person...must be protected from disclosure to third parties". ${ }^{40}$ Another article states that: ${ }^{41}$

No one may be subjected to discrimination based on genetic characteristics that is intended to diminish or has the effect of diminishing human dignity or impairing the right to be treated equally.

In spite of this overall trend suggesting intervention to limit access by insurers, the fundamental question remains whether protection from third parties such as insurers

39 D C Wertz "Guidelines on Ethical Issues in Medical Genetics and the Provision of Genetic Services" (WHO, Geneva, 1995) 79, Recommendation 6.

40 UNESCO "Revised Outline of a Declaration on the Protection of the Human Genome" (International Bioethics Committee, Paris, March 1996) Article 8; UNESCO "Preliminary Draft for a Universal Declaration on the Human Genome and Human Rights" (International Bioethics Committee, USA, 1996) ["Protection of the Human Genome"].

41 "Protection of the Human Genome", above n 40, Art 7. 
should be through strengthened human rights legislation, heightened protection of medical records, or though a specific statute prohibiting genetic discrimination.

\section{B United States}

In the United States, where there is no universal health care system, the great concern is access to, and availability of, health insurance. Some time ago, citizens realised that insurance companies and employers ${ }^{42}$ could discriminate against them if their medical files contained evidence that they suffered from, or were predisposed to, costly diseases.

State legislators and Members of Congress sprang into action with Bills to protect genetic privacy and prohibit genetic discrimination. By 1997 at least 15 states had enacted genetic privacy laws. More than 75 Bills are pending in more than 30 states, and several federal Bills have been introduced. Much of the proposed state legislation has been eclipsed by a new federal law.

The Health Insurance Portability and Accountability Act 1996 (HIPAA) provides an important new protection for people who want to undergo genetic testing but fear discrimination by health insurers if test results indicate an increased risk of developing a serious disease. It curtails the right of health insurers to limit coverage of apparently healthy applicants because of 'pre-existing conditions', including susceptibilities predicted by genetic tests. Coverage cannot exclude conditions which may exist in the future. $^{43}$ This means that individuals who decide to undergo pre-predispositional genetic testing will face relatively little risk of discrimination in health insurance.

\section{The European Community}

The major Community-wide initiative is a Commission of European Communities funded report by Euroscreen, ${ }^{44}$ which is currently consulting with the insurance industry with a view to developing an agreed policy on the use of genetic information. ${ }^{45}$ In the meantime, some European countries have taken independent legislative action to control the use of genetic information.

42 Employers are relevant in the American environment, as a great proportion of the population receive health insurance cover as part of an employment contract.

43 Section 101.

44 Euroscreen "Genetic Screening: Ethical and Philosophical Perspectives" (February 1997).

45 The next Euroscreen Report is expected to be released in 1999, and will address some of the major issues: (1)whether there is anything special about genetic information as opposed to other medical information; and (2) implications of genetic information for insurance companies. 
Norway has introduced statutory prohibitions to forbid the receipt, possession, or use of information concerning individuals which is derived from genetic test, as well as forbidding the release of medical information to insurers without consent. ${ }^{46}$ Belgium $^{47}$ has adopted laws to prevent insurers from requesting or using genetic information to underwrite life insurance contracts. France and the Netherlands have adopted moratoria on access to genetic information by insurers.

In the United Kingdom the Association of British Insurers (ABI) announced recently that people wishing to take out new life insurance will not be asked to take genetic tests when applying for life insurance. ${ }^{48}$ Individual insurance companies will continue to decide whether applicants will be required to disclose the results of any genetic tests already undertaken.

The ABI has also set up a Genetics Committee to liaise with geneticists and other relevant bodies, and consult with the public on a Code of Practice on genetic data. The Code seeks to establish standards and guiding principles regarding the proper use of genetic information by insurers. The Association intends to review the present position in 1999 in order to take current genetic developments into account.

\section{Australia}

Comprehensive genetic privacy legislation has not been enacted in Australia, although the Privacy Commissioner has issued an information paper identifying problems in this arena. ${ }^{49}$ Health insurers have been silent on the subject, whereas the Life Investment and Superannuation Association of Australia (LISA) has been proactive in releasing a special Code of Conduct in relation to the use of genetic test results. The Code suggests that insurers should be able to request existing genetic test results only with express written informed consent, and that results should only be used to classify the risk of the individual concerned, but not of other blood relatives. ${ }^{50}$

46 Act Relating to the Application of Biotechnology in Medicine 1994.

47 Loi sur le Contrat d'Assurance Terrestre 1992.

48 Association of British Insurers "Life Insurance and Genetics - A Policy Statement" (London, February 1997).

49 Privacy Commissioner of Australia, The Privacy Implications of Genetic Testing, Human Rights and Equal Opportunity Commission, September 1996.

50 There is a real issue here which relates back to one of the factors which makes genetic information special, and deserving of special treatment and protections. That issue is the familial nature of the information and the fact that information can be gleaned about other blood relatives from genetic test results from only one family member. 


\section{PROTECTION OF GENETIC INFORMATION PRIVACY IN NEW ZEALAND}

\section{A The Role of the Privacy Act 1993 and the Health Information Privacy Code 1994}

The government has a regulatory role to play in protecting consumers of genetic services by ensuring that genetic information is safely stored, with strict controls on its disclosure and use.

The Privacy Act 1993 (the Act) starts from the premise of control by individuals of information about themselves. The concept of privacy has evolved to include recognition of an individual's information profile and personal history. The Act sets out the principles relating to the collection, storage, use and disclosure of any information about any individual. The rules of the Health Information Privacy Code 1994 (the HIPC) apply, similarly, to health information. The overriding question is whether these principles and rules are sufficiently robust to govern genetic information.

In the Act "personal information" is broadly defined as meaning "information about an identifiable individual". ${ }^{51}$ In the HIPC "health information"52 is defined as meaning information about an identifiable individual that is: ${ }^{53}$

(a) information about the health of that individual, including his or her medical history; information about any disabilities the individual has, or has had;...

(c) information provided by that individual derived from the testing or examination of any body part, or any bodily substance of that individual;

(d) information about that individual which is collected before or in the course of, an incidental to, the provision of any health service or disability service to that individual; $\ldots$.

(i) an agency which provides health, disability or medical insurance, but only in respect of providing that insurance.

Both "personal information" and "health information" are broad enough, therefore, to include the fact that a person has undergone genetic testing, any discussions that the person may have had about her genetic testing, and any information about the identity of her biological relatives. The wide definition of "agency" in the Act applies to both public

51 Section 2(1).

52 Part I of the Code defines the scope of "health information" as that "information held by a health agency".

53 It is interesting to note that the Alberta Freedom of Information and Privacy Act 1994 definition of "personal information" expressly includes "the individual's inheritable characteristics". 
and private sector persons or bodies which would include insurance companies. In the HIPC, "health agencies" expressly includes health insurers. ${ }^{54}$

Personal information may be collected by an agency only where it is necessary for a lawful purpose connected with a function or activity of that agency. ${ }^{55}$ A compelling case would have to be made in respect of genetic information. The fact that it may be useful or relevant in the future would not satisfy this principle. If an insurer were collecting genetic information in order to offer differential coverage or conditions to individuals with a defective genotype, and if this were to come within the prohibited grounds for discrimination under the Human Rights Act 1993, then this may not be a "lawful" purpose under Principle 1 of the Privacy Act.

Agencies should collect personal information directly from the individual concerned, ${ }^{56}$ but in the context of genetic testing, information about family members will be unavoidably obtained. An exception in the HIPC permits collection of information from someone other than the individual, for the purposes of assembling a family or genetic history. ${ }^{57}$ That is important as, for many genetic diseases, it may be necessary to test not just an individual but also other family members.

When personal information is collected from an individual an agency must ensure, as far as practicable, that the individual concerned is aware of the fact that the information is being collected, the purpose for which the information is being collected, the intended recipients of the information, any consequences of not providing the information, and her rights of access to, and correction of, the information collected. ${ }^{58}$ In the genetic testing context, adhering to these requirements is particularly important when an individual is applying for insurance and supplying a medical history, or when being examined or assessed by a doctor employed by the insurer.

A significant safeguard in place is that information can only be used for the purposes for which it was collected or for directly related purposes. ${ }^{59}$ That means that genetic information collected by a health insurer should not then be used when an individual seeks life insurance, even though the information may be held by the same agency. The

54 Part I, Rule 4(2)(j).

55 Privacy Act 1993 ("Privacy Act"), Principle 1; Health Information Privacy Code 1994 ("HIPC") Rule 1

56 Privacy Act, Principle 2; HIPC, Rule 2.

57 HIPC, Rule 2 (2)(e).

58 Privacy Act, Principle 3; HIPC, Rule 3.

59 Privacy Act, Principle 10; HIPC, Rule 10. 
insurer should elicit a written authorisation for the information to be used, ensuring always that the insured is giving their fully informed consent to the collection and use of genetic information. This safeguard would also come into play if another blood relative were also insured by, or applied for insurance with, the same insurer as the person who has supplied genetic test results to the company.

The information gleaned from the test results of the one individual, must not be used to assess the health status of another individual. That is particularly important given the familial nature of genetic information. There is no reason why this protection should be weakened by the "family or genetic history" exception mentioned above. ${ }^{60}$ While an agency may not keep information longer than is required for the purposes for which it may be lawfully used, ${ }^{61}$ the HIPC allows information to kept for as long as it is required to provide the health service. ${ }^{62}$ That could well mean that an insurer could justify the long-term retention of genetic test results.

There are also limits placed upon the disclosure of personal or health information held by an agency. The agency cannot disclose information unless the disclosure is either one of the purposes in connection with which the information was obtained, or is directly related to the purposes in connection with which the information was obtained. ${ }^{63}$ Disclosure is sanctioned if authorised by the individual concerned ${ }^{64}$ or if it is to the individual concerned. ${ }^{65}$

The HIPC rule differs from the principle in the Act and, in particular, places considerable emphasis on eliciting authorisation from the individual concerned. In the genetic testing and insurance context, the issue of the genuineness of the consent given must be considered. There is a very real likelihood that disclosure of genetic test results could amount to coercion if applicants knew they would be denied insurance if they were to refuse to supply results, or even refuse to undergo genetic testing. ${ }^{66}$

\author{
60 HIPC, Rule 2(2)(e). \\ 61 Privacy Act, Principle 9. \\ 62 HIPC, Rule 9. \\ 63 Privacy Act, Principle 11; HIPC, Rule 11. \\ 64 Privacy Act, Principle 11 (d). \\ 65 Privacy Act, Principle 11 (c). \\ 66 As discussed in Part IVA.
}




\section{B Insurance Company Compliance with the Privacy Act and the Health Information Privacy Code}

Research into insurance company compliance with the Principles of the Privacy Act offered some interesting results. It is commonplace for a health insurer to request further information before paying out on a reimbursement or other type of claim. Typically, when such a report from a doctor is required, the insured patient is asked to take a report form, complete with a "privacy sign-off" to her doctor. The GP completes the form and returns it to the company's medical referee.

By way of comparison, the application for one life insurance policy goes even further, saying under the heading "Your Declaration and Privacy Act 1993 Acknowledgements":67

I authorise:

(a) [the company] to obtain at any time from any employer, doctor, hospital, health agency, insurance office, government agency or any other person any information [the company] may require to perform, or complete any of the purposes in connection with which I have provided personal information to [the company].

(b) Any such person to release to [the company] any personal information the person holds concerning me.

The problems associated with such blanket authorisations are considerable in the genetics context. Many of the problems have already been raised and discussed, but it is important that members of the public are aware of the extent of the authorisation they are giving their insurers. The Privacy Commissioner recently acknowledged that many doctors are concerned at the blanket authorisations used by some health insurers. Patients have no choice but to sign if they want their claims processed. The Commissioner said: 68

I am aware that some doctors consider that they have been presented with unreasonable requests for information...which does not seem relevant. They have wondered whether the patient anticipated what could be requested using the authorisation. I think the concern about blanket authorisations is legitimate.

The relevant principles are that disclosure must be revocable, and patients must be informed of this right to revoke. Recipients of information must be notified that the

67 Policy application supplied by a major New Zealand life insurance company.

68 B Slane "Information Protection in Healthcare: Knowledge at What Price?" Address by the Privacy Commissioner (Health Summit, July 1998). 
disclosed information is confidential, and the information must not be re-disclosed without the specific written consent of the patient.

\section{Storage of Genetic Information}

At present, there is no national genetic register in New Zealand. ${ }^{69}$ Testing samples are stored along with test results and analysis in the Cytogenetics Departments of public hospitals. ${ }^{70}$ Test results are not recorded in current hospital-based computer programmes without written informed patient consent.

\section{Concluding Comments}

Genetic privacy must be rigorously protected. In respect of health care coverage it is recommended that: (1) information about past, present, or future health status, including genetic information, should not be used to deny health coverage or services to anyone; and that (2) access to health insurance cover should not depend on the disclosure by individuals or families of information, including genetic information about present, past, or future health status.

The Privacy Commissioner has acknowledged that he is permitted under the Act to issue specific codes of practice which could modify the general information privacy principles in ways relevant to the problems posed by the collection, use, and disclosure of genetic information. He has suggested though, that: ${ }^{71}$

it would be a matter of public policy as to whether or not that is appropriately done under delegated legislation by a Privacy Commissioner or whether the issues should be faced by our

legislators in primary legislation by an act of the New Zealand Parliament.

\section{PROTECTION AGAINST GENETIC DISCRIMINATION: THE ROLE OF THE HUMAN RIGHTS ACT 1993}

The insurance industry tends to favour self-regulation over legislation, and New Zealand insurers have worked closely with the Human Rights Commission to prepare

69 See J Dixon, J Winship and D Webster, Priorities for Genetic Services in New Zealand for the National Advisory Committee on Core Health and Disability Support Services, July 1995.

70 Currently, in New Zealand, there are only two specialist clinical geneticists, Dr Joanne Dixon, Central Regional Genetics Service and Dr J Winship, Northern Regional Genetics Service. It is interesting to note that Sexual Health Clinics which work out of hospitals also keep their encoded patient records separate from the hospital information system, in order to accord the highest possible security to such sensitive patient information.

71 B Slane "Whose Genes Are They Anyway? The Use and Misuse of Human Genetic Information" (Health Research Council Conference, July 1995). 
industry guidelines based on the Human Rights Act 1993 (the "HRA"). ${ }^{72}$ The HRA prohibits discrimination in the provision of "goods, facilities or services to the public". ${ }^{73}$ As the term "facilities" expressly includes insurance, insurers cannot refuse to offer insurance, or treat persons less favourably, on the basis of disability.

The definition of "disability" within the HRA arguably covers the physical manifestation of any genetic defect and is potentially broad enough to include genetic carrier or susceptibility status in "[a]ny abnormality of... physiological, or anatomical structure or function". ${ }^{74}$

In addition, discrimination based on a person's family history and an assumed or suspected disability could also bring genetic predisposition within the parameters of the HRA. ${ }^{75}$ In the interests of clarity and certainty, amending the HRA to remove any doubt that defective genes can cause illness or disease would be a progressive step.

Although an insurer cannot refuse to insure on the basis that a genetic predisposition is a pre-existing condition, ${ }^{76}$ the exclusion of a pre-existing condition does not contravene the HRA, as there is no refusal to insure nor any less favourable treatment. Those who are already sick cannot be discriminated against because of the risk of future illness - they already have the illness. ${ }^{77}$ Genetic testing warrants separate analysis in the guidelines, which state that, while insurance companies can request that existing genetic test results are made available for the purpose of classifying a risk, they cannot insist that applicants undergo genetic tests. ${ }^{78}$

In section 48, the HRA expressly permits insurers to rely on disability for the purposes of deciding the terms and conditions upon which a person is to be offered insurance. To come within the exemption, the differential treatment must be reasonable and based on actuarial or statistical data or, where none exists, on medical or actuarial

72 Insurance Guidelines (Human Rights Commission, Auckland, 1997), prepared pursuant to s 5(1)(d) Human Rights Act 1993.

73 Section 44.

74 Section 21(h)(v), emphasis added.

75 Section 21(2).

76 A pre-existing condition is one that the proposer has at the time of application for insurance.

77 United States legislation, the Americans with Disabilities Act 1990 has recently been amended to limit access to genetic information relating to actual conditions, whereas information about asymptomatic status cannot be used.

78 At common law the insurance contract could be avoided for non-disclosure if genetic test results were not disclosed. 
advice or opinion. ${ }^{79}$ Although there is as yet no consensus on the issues surrounding genetic testing in insurance, it seems that this provision effectively approves genetic discrimination in the provision of health and life insurance. The provision must be reexamined and, if necessary, amended to provide sufficient protection for individuals. To date, the HRA remains untested in the area of genetic discrimination

Obtaining adequate health insurance in a system becoming more and more dominated by private health insurance is crucial. ${ }^{80}$ Giving a person the option of withholding the information from their medical record may reduce insurance discrimination but it may ultimately have a negative impact on that person's care. Broader solutions would be to improve the confidentiality laws governing all medical information, to prohibit health insurance discrimination against all pre-existing conditions and risks of future disease premised on genetic test results. Another option is that the risk of genetic discrimination could be reduced by insurers considering a moratorium on the use of genetic tests in underwriting.

\section{CONCLUSION}

Developments in genetics are occurring at lightning speed. Can the legal tortoise keep pace with the scientific hare? Enacting genetic-specific legislation may be a poor option as good laws are difficult to make and hard to change. Governments can do many things in addition to making laws. They can educate the public, and establish advisory or supervisory machinery. The respective Commissioners of Privacy and Human Rights are an integral part of the current supervisory machinery when considering issues related to genetic privacy and discrimination.

New Zealand is not well-served in any coherent, universal way when ethical and legal aspects of the new human genetics require consideration. To remedy this it is recommended that an advisory group ${ }^{81}$ be set up whose terms of reference would be to: (1) monitor developments in human genetics; (2) facilitate discussion with all relevant persons, groups and bodies; and (3) report on issues arising from new developments in human genetics that can be expected to have wider ethical, social, economic, and legal consequences. Those terms would include, for example, the insurance industry. The

79 Geoff Rashbrooke, Government Actuary, notes that his function is advisory only (Telephone interview, Wellington, July 1997).

80 Dr Tim Smart, Executive Director, Health Insurance Association, suggests that some $37 \%$ of the New Zealand population (approximately 1.4 million), New Zealanders are covered by private health insurance policies. Although this is an informal statistic, the number is significant.

81 Possible members of the group would include: geneticists, medical ethicists, lawyers, and representatives from Human Rights Commission, Health and Disability Commissioner, Privacy Commissioner, Ministry of Health and the insurance industry. 
advisory group could also suggest ways of educating the public and increasing its understanding of the new genetics.

Current law in New Zealand is not robust enough to adequately protect the privacy of personal genetic information. It may not, however, be necessary to enact genetic-specific legislation. The pros and cons of enacting genetic-specific legislation require further debate. There may be, in the near future, a need for legal safeguards against compulsory genetic screening. Although it may be argued, somewhat speciously, that insurance is not a compulsory undertaking, that fine line between permission, informed consent and coercion can easily become blurred.

Legislators, insurance providers, and the public are starting to pay greater attention to issues surrounding the protection of genetic information. Currently, the level of protection available in New Zealand is uncertain, and quite possibly inadequate. Genetic information is of such a fundamentally different nature in its unique ability to identify, classify and differentiate a person, that it cannot always be treated as an extension of general medical information. Genetic information must be given special status in order to protect individual privacy, especially with respect to predictive genetic information. Without this special status there is a significant risk of harm, including discrimination in insurance.

In the final analysis it is as well to recognise that: "each new power won by man is a power over man as well." 82

82 CS Lewis The Abolition of Man (MacMillan, London, 1965) 71. 
